\title{
BMJ
}

\section{Effects of statins in patients with chronic kidney disease: meta-analysis and meta-regression of randomised controlled trials}

\author{
Giovanni F M Strippoli, editor of Cochrane Renal Group, ${ }^{1,2,3}$ Sankar D Navaneethan, clinical fellow in \\ nephrology, ${ }^{4}$ David W Johnson, professor of nephrology, ${ }^{5}$ Vlado Perkovic, associate director (clinical \\ research), ${ }^{6}$ Fabio Pellegrini, biostatistician, ${ }^{2}$ Antonio Nicolucci, head, ${ }^{2}$ Jonathan C Craig, editor in chief of \\ Cochrane Renal Group and associate professor of epidemiology ${ }^{1,3}$
}

${ }^{1}$ NHMRC Centre for Clinical Research Excellence in Renal Medicine, School of Public Health University of Sydney, Australia

${ }^{2}$ Department of Clinical

Pharmacology and Epidemiology,

Mario Negri Sud Consortium,

S Maria Imbaro (Ch), Italy

${ }^{3}$ Cochrane Renal Group, Sydney

${ }^{4}$ Division of Nephrology,

University of Rochester, 601

Elmwood Avenue, Box 675, NY

14623, USA

${ }_{5}^{5}$ University of Queensland,

Brisbane, Australia

${ }^{6}$ George Institute for Internationa Health, Sydney

Correspondence to:

S D Navaneethan

sankardass@hotmail.com

doi:10.1136/bmi.39472.580984.AE

\section{ABSTRACT}

Objective To analyse the benefits and harms of statins in patients with chronic kidney disease (pre-dialysis, dialysis, and transplant populations).

Design Meta-analysis.

Data sources Cochrane Central Register of Controlled Trials, Medline, Embase, and Renal Health Library (July 2006).

Study selection Randomised and quasi-randomised controlled trials of statins compared with placebo or other statins in chronic kidney disease.

Data extraction and analysis Two reviewers independently assessed trials for inclusion, extracted data, and assessed trial quality. Differences were resolved by consensus. Treatment effects were summarised as relative risks or weighted mean differences with $95 \%$ confidence intervals by using a random effects model. Results Fifty trials (30144 patients) were included. Compared with placebo, statins significantly reduced total cholesterol (42 studies, 6390 patients; weighted mean difference $-42.28 \mathrm{mg} / \mathrm{dl}(1.10 \mathrm{mmol} / \mathrm{l}), 95 \%$ confidence interval -47.25 to -37.32 ), low density lipoprotein cholesterol (39 studies, 6216 patients; $-43.12 \mathrm{mg} / \mathrm{dl}$ (1.12 mmol/l), -47.85 to -38.40$)$, and proteinuria (g/24 hours) (6 trials, 311 patients; $-0.73 \mathrm{~g} /$ 24 hour, -0.95 to -0.52 ) but did not improve glomerular filtration rate (11 studies, 548 patients; $1.48 \mathrm{ml} / \mathrm{min}$ $(0.02 \mathrm{ml} / \mathrm{s}),-2.32$ to 5.28$)$. Fatal cardiovascular events (43 studies, 23266 patients; relative risk $0.81,0.73$ to 0.90 ) and non-fatal cardiovascular events (8 studies, 22863 patients; $0.78,0.73$ to 0.84 ) were reduced with statins, but statins had no significant effect on all cause mortality (44 studies, 23665 patients; 0.92, 0.82 to 1.03). Meta-regression analysis showed that treatment effects did not vary significantly with stage of chronic kidney disease. The side effect profile of statins was similar to that of placebo. Most of the available studies were small and of suboptimal quality; mortality data were provided by a few large trials only.

Conclusion Statins significantly reduce lipid

concentrations and cardiovascular end points in patients with chronic kidney disease, irrespective of stage of disease, but no benefit on all cause mortality or the role of statins in primary prevention has been established. Renoprotective effects of statins are uncertain because of relatively sparse data and possible outcomes reporting bias.

\section{INTRODUCTION}

The number of people affected by chronic kidney disease or who need renal replacement treatment is steadily increasing. ${ }^{1}$ Although cardiovascular mortality is decreasing in the general population, cardiovascular disease still accounts for by far the largest proportion of fatalities in people with chronic kidney disease. $^{2}$ Dyslipidaemia (including increased total cholesterol, triglycerides, and low density lipoprotein cholesterol concentrations and decreased high density lipoprotein cholesterol concentrations) is one of several factors (including hypertension, diabetes, and smoking) that have been implicated in the increased cardiovascular risk associated with chronic kidney disease and also in the progression of renal damage. ${ }^{3-5}$ Optimal management of dyslipidaemia, particularly reduction of low density lipoprotein cholesterol, should therefore lead to both cardiovascular and renal benefits.

Clinical trials in the general population and in people with established cardiovascular disease have found a strong, consistent, and independent association between reducing lipid concentrations, primarily of low density lipoprotein cholesterol, and the risk of all cause mortality and cardiovascular mortality, ${ }^{67}$ with a linear reduction in the risk of major vascular events of about $20 \%$ for every $\mathrm{mmol} / \mathrm{l}$ reduction in low density lipoprotein cholesterol. ${ }^{8-10}$ Data in people with chronic kidney disease have been conflicting; some observational studies in dialysis patients have shown a clear, linear relation between low density lipoprotein cholesterol and cardiovascular end points, whereas others have not. ${ }^{112}$ Few randomised trials have been done in patients with chronic kidney disease. The most recent 
large trial in patients with diabetes who needed dialysis did not show a significant reduction in cardiovascular end points with statin treatment. ${ }^{13}$

International guidelines reflect these uncertainties; some recommend that cholesterol concentrations should be lowered in chronic kidney disease, ${ }^{14}{ }^{15}$ but others suggest that more data are needed. ${ }^{16}{ }^{17}$ In two recent meta-analyses, claims of improved renal outcomes have been made, encouraging broader adoption of statins in patients with pre-dialysis (stages I-IV) chronic kidney disease. ${ }^{18}{ }^{19}$ Douglas et al reported the beneficial effects of statins in patients with overt proteinuria (protein excretion $>300 \mathrm{mg} /$ day) but not in those with microalbuminuria or normoalbuminuria. Similarly, Sandhu et al reported a slowing of the decline in glomerular filtration rate in patients with chronic kidney disease and concomitant cardiovascular disease ( $0.93 \mathrm{ml} / \mathrm{min} /$ year slower than in control patients), along with improvement in proteinuria. Neither of these reviews intended to analyse the effect of statins on lipid concentrations or mortality in patients with kidney disease specifically on the basis of the stage of kidney disease (pre-dialysis, dialysis, and transplantation). ${ }^{1819}$ The aim of our study was to evaluate the efficacy and safety of statins for renal and cardiovascular outcomes in all stages of chronic kidney disease (pre-dialysis, dialysis, and transplantation).

\section{METHODS}

\section{Inclusion criteria}

We included all randomised controlled trials and quasi-randomised controlled trials (method of allocating participants to different forms of care that is not truly random) of any statin against placebo, no treatment, or another statin in adult patients with chronic kidney disease, including substudies of patients with chronic kidney disease recruited within large scale statin trials. We defined patients with chronic kidney disease as those who were having maintenance dialysis treatment, had had renal transplantation, had an elevated baseline mean serum creatinine $(>1.4 \mathrm{mg} / \mathrm{dl}$ $(0.121 \mathrm{mmol} / \mathrm{l})$ or as defined by authors), or had an impairment of the glomerular filtration rate as defined by the kidney disease outcome quality initiative guidelines with values of glomerular filtration rate $<60 \mathrm{ml} / \mathrm{min} / 1.73 \mathrm{~m}^{2}$ (stages 3-5) or $>60 \mathrm{ml} / \mathrm{min} / 1.73$ $\mathrm{m}^{2}$ along with other markers of kidney damage such as proteinuria. ${ }^{20}$ We excluded studies with patients defined as having "renal impairment" but where we could not ascertain the baseline glomerular filtration rate or creatinine concentration. We included only randomised controlled trials of at least eight weeks' duration, because studies with a shorter follow-up period would not allow detection of significant changes in lipid concentrations or other major patient level outcomes. We excluded studies in participants with impaired liver function tests or elevated creatinine phosphokinase concentrations and those that examined the efficacy of combination treatments with other lipid lowering agents.

\section{Data sources and searches}

We searched Medline, Embase, the Cochrane Central Register, and the Renal Health Library of the Cochrane Renal Group in July 2006 with the following terms: chronic kidney disease, dialysis, haemodialysis, peritoneal dialysis, renal transplantation, kidney transplantation, acute renal allograft rejection, renal allograft rejection, hypercholesterolaemia, hyperlipidaemia, dyslipidaemia, HMG-CoA reductase inhibitors, and statins. We also used text words for all statins. The search strategy used is available from the authors. We considered randomised controlled trials without language restriction. We searched the reference lists of identified trials and review articles for additional trials. We sought information about unpublished and ongoing randomised controlled trials from authors of the included randomised controlled trials, drug companies, and experts in the field.

\section{Data collection and analysis}

Two authors independently reviewed literature searches to identify relevant trials that met the inclusion criteria. We extracted data on study sample, population characteristics (age, race, sex, and baseline comorbidities), interventions (type and dose of statin, duration of treatment), co-interventions (administered in a non-randomised fashion), and the methodological quality of the trials. We extracted data on the following outcomes: all cause mortality; fatal cardiovascular and cerebrovascular events; non-fatal cardiovascular and cerebrovascular events (defined as myocardial infarction, stroke, sudden death, or composites of these end points) separately; end stage renal disease; doubling of serum creatinine concentration; lipid concentrations at the end of treatment (total cholesterol, low density lipoprotein cholesterol, high density lipoprotein cholesterol, triglycerides); creatinine clearance $(\mathrm{ml} / \mathrm{min}$ or $\mathrm{ml} / \mathrm{min} / 1.73 \mathrm{~m}^{2}$ ) and 24 hour urinary protein excretion $(\mathrm{g} / 24 \mathrm{~h})$ (in trials of patients with pre-dialysis chronic kidney disease who did not need renal replacement treatment); acute allograft rejection rates (in trials of transplant recipients); adverse events (including elevated liver function tests and elevated creatinine kinase concentrations); and missing patient data owing to withdrawals, non-intention to treat analysis, and loss to follow-up. Some trials included different populations (pre-dialysis, dialysis, transplant) and thus contributed to more than one analysis, so we have separated the individual comparisons for each population of interest and included them in the relevant meta-analysis by comparisons or subsets rather than for trials.

We used relative risk with $95 \%$ confidence intervals to analyse dichotomous data (all cause mortality, fatal and non-fatal cardiovascular or cerebrovascular events, acute allograft rejection, and adverse events). We pooled risk estimates from individual trials by using the Der Simonian-Laird random effects model. ${ }^{21}$ Where continuous measurements of outcomes were used (24 hour urinary protein excretion, creatinine clearance, lipid concentrations), we calculated the 
weighted mean difference with $95 \%$ confidence intervals by using the values of the outcome at the end of treatment. We used end of treatment data because few trials reported changes in the value of these outcomes from beginning to end of treatment with a variance estimator. We contacted authors for clarification about end points (such as mortality, cardiovascular events, renal function, lipid parameters, toxicity) up to three times.

We used the heterogeneity $\chi^{2}$ (Cochran Q) statistic and the $\mathrm{I}^{2}$ test to formally analyse heterogeneity across included trials. ${ }^{22}$ We did subgroup analysis and random effects univariate and multivariate metaregression where possible to explore the role of potential sources of heterogeneity related to the participants (age, race, sex, stage of chronic kidney disease (pre-dialysis, dialysis, or transplant), and baseline risk covariates), the agent used (different types and doses of statins, different duration of treatment and modes of administration) and trial quality (allocation concealment, blinding, use of intention to treat analysis, and proportions of patients lost to follow-up) on the effect of the interventions. We always analysed trials done in pre-dialysis, dialysis, and transplant populations separately and pooled the results when formal tests of interaction indicated no significant

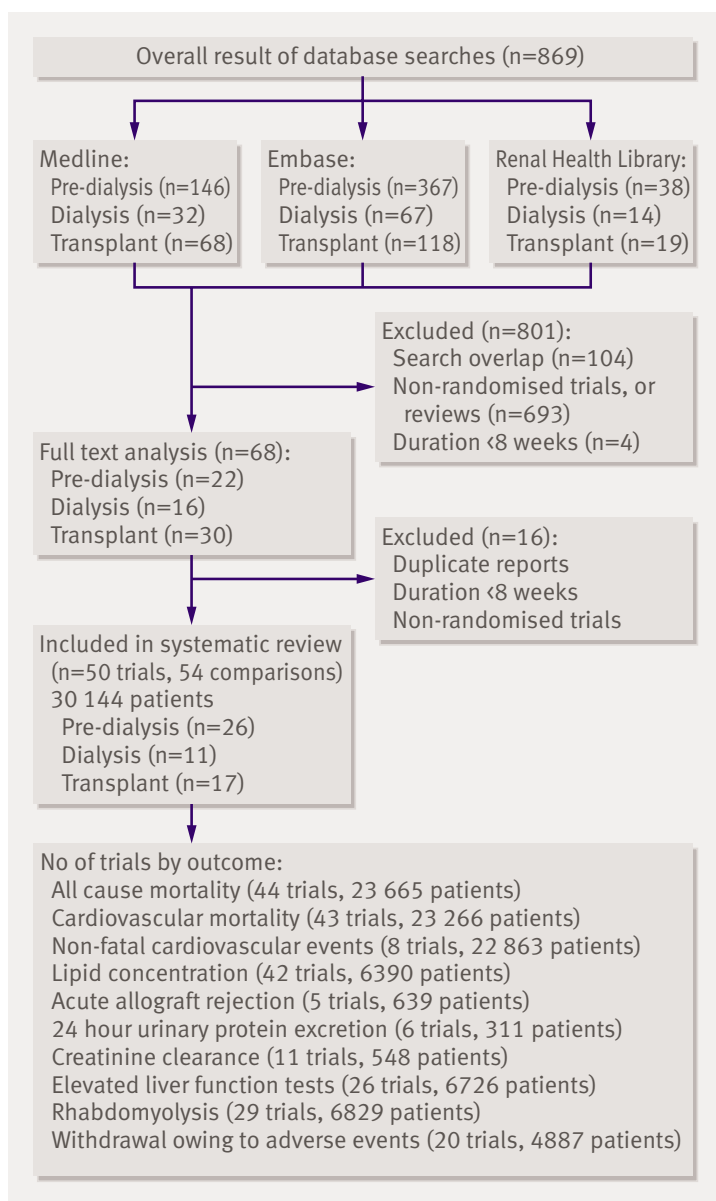

Fig 1 Flow chart showing number of citations retrieved by individual searches and number of trials included in review difference between the estimates from the separate groups. We used RevMan version 4.2.10 and SAS 9.1.2 for analyses.

\section{Quality assessment}

At least two authors independently assessed the methodological quality of included randomised controlled trials by using standard domains: allocation concealment (adequate if sequentially labelled, sealed and opaque envelopes or central or pharmacy randomisation was used; inadequate when pseudorandomisation was used; unclear in all other cases); blinding of investigators, participants, and outcome assessors; use of intention to treat analysis; completeness of follow-up. Discrepancies in data extraction were resolved by discussion among authors. Where more than one publication of a trial existed, we included only the publication with the most complete data.

\section{RESULTS}

\section{Search results}

The combined search of Medline, Embase, and the Cochrane Central Register of randomised controlled trials identified 869 articles, of which we excluded 801 because they were not randomised controlled trials or they evaluated interventions that were not relevant to this review (such as fibrates or other lipid lowering agents). Full text assessment of the remaining 68 potentially relevant articles resulted in identification of 50 eligible randomised controlled trials with 54 comparisons of statins versus placebo or no treatment (comparisons: pre-dialysis, $\mathrm{n}=26$; dialysis, $\mathrm{n}=11$; transplant, $\mathrm{n}=17$ ), which included 30144 patients (fig 1). ${ }^{13 w 1-w 49}$

\section{Trial characteristics}

Twenty six randomised controlled trials or subsets of randomised controlled trials in pre-dialysis chronic kidney disease populations, 11 randomised controlled trials or subsets of randomised controlled trials in haemodialysis and peritoneal dialysis patients, and 17 randomised controlled trials or subsets of randomised controlled trials in renal transplant recipients evaluated the effects of statins versus placebo. All trials studied the effect of statins on lipid concentrations and safety. Of the 44 trials that reported mortality, the pravastatin pooling project (PPP, a subgroup analysis of patients with renal insufficiency in the cholesterol and recurrent events (CARE) trial, long term intervention with pravastatin in ischemic disease (LIPID) study, and west of Scotland coronary prevention project study (WOSCOPS)), ${ }^{\text {w10 }}$ the atorvastatin in patients with type 2 diabetes mellitus undergoing hemodialysis (4D) trial, ${ }^{13}$ and the assessment of Lescol in renal transplantation (ALERT) trial ${ }^{\mathrm{w} 42}$ provided most event data. We treated the pravastatin pooling project as one trial because we could not get separate trial level data.

The 26 randomised controlled trials or subsets of randomised controlled trials in pre-dialysis chronic kidney disease enrolled participants with diabetic nephropathy $(\mathrm{n}=6)$, hypertensive nephropathy $(\mathrm{n}=2)$, 
or various forms of nephrotic and non-nephrotic glomerulonephritis. One trial ( $\mathrm{n}=20$ patients) was done in patients with polycystic kidney disease. ${ }^{\text {w12 }}$ Fifteen of these randomised controlled trials evaluated the potential renoprotective effect of statins, particularly their effects on 24 hour urinary protein excretion. In essence, most of these studies enrolled patients with early or late stages of chronic kidney disease and with a history of coronary heart disease. These studies did not include patients with moderate chronic kidney disease but without cardiac disease.

Five randomised controlled trials in renal transplant recipients reported biopsy proved acute allograft rejection rates, but no trial reported the effects on chronic allograft nephropathy. ${ }^{\text {w35-w39 }}$ Liver function tests and creatinine phosphokinase concentrations were the only safety parameters reported consistently in all trials. Follow-up ranged from two months to 60 months in all trials, and several different statins were used. The UK-HARP study included pre-dialysis, dialysis, and renal transplant patients, ${ }^{\mathrm{w} 13}$ and the study by Stegmayr et al included both pre-dialysis and dialysis patients. ${ }^{\text {w8 }}$ Table 1 details additional characteristics of the populations and interventions in the included randomised controlled trials.

\section{Trial quality}

The methodological quality of many trials was suboptimal. Concealment of allocation was adequate in $11(22 \%)$ randomised controlled trials, clearly inadequate in $9(18 \%)$, and unclear in the remainder. Participants, investigators, and outcome assessors were blinded in only $10(20 \%)$ randomised controlled trials, and only $10(20 \%)$ randomised controlled trials were analysed on an intention to treat basis. The dropout rate was less than $10 \%$ in $43(86 \%)$ randomised controlled trials, between $10 \%$ and $19 \%$ in $4(8 \%), 20-39 \%$ in 2 $(4 \%)$, and over $40 \%$ in only $1(2 \%)$ trial.

Effect of statins on surrogate end points in chronic kidney disease

\section{Total cholesterol}

Total cholesterol concentrations were significantly lower with statins than with placebo (42 comparisons, 6390 patients; weighted mean difference $-42.28 \mathrm{mg} / \mathrm{dl}$ $(-1.10 \mathrm{mmol} / \mathrm{l}), 95 \%$ confidence interval -47.25 to -37.32 ) (table 2). We found significant heterogeneity for this outcome (heterogeneity $\chi^{2}=804.09, \mathrm{I}^{2}=94.9 \%$ ), which was largely explained by the type of statin (38.42\% of heterogeneity) and the baseline cholesterol concentration $(60.73 \%$ of heterogeneity; greater differences in patients with higher baseline values). Stage of chronic kidney disease was not an effect modifier. The cholesterol lowering effect of atorvastatin and cerivastatin was significantly higher than that of other statins (such as pravastatin or fluvastatin) and increased proportionally with increasing baseline cholesterol concentrations (model 2, table 3 ).

Low density lipoprotein cholesterol

Low density lipoprotein cholesterol concentrations were significantly lower with statins than with placebo (39 comparisons, 6216 patients; weighted mean difference $-43.12 \mathrm{mg} / \mathrm{dl}(-1.12 \mathrm{mmol} / \mathrm{l}),-47.85$ to -38.40) (table 2). We found significant evidence of heterogeneity between agents (for example, cerivastatin $v$ pravastatin or fluvastatin). The type of statin explained $38.42 \%$ of existing heterogeneity in the effect of statins on total cholesterol concentrations at the end of treatment and $10.99 \%$ of that on low density lipoprotein cholesterol (model 2, table 3 ).

\section{High density lipoprotein cholesterol}

Statins had no significant effect compared with placebo on the concentration of high density lipoprotein cholesterol in chronic kidney disease (40 comparisons, 5621 patients; weighted mean difference $0.41 \mathrm{mg} / \mathrm{dl}$ (0.01 mmol/l), 0.78 to 1.60 ) (table 2). We found considerable heterogeneity (heterogeneity $\chi^{2}=693.78$, $\mathrm{I}^{2}=94.4 \%$ ), but this was not explained by stage of chronic kidney disease.

\section{Triglycerides}

We found a significant reduction in triglyceride concentrations with statins in comparison with placebo (39 comparisons, 5569 patients; weighted mean difference $-23.71 \mathrm{mg} / \mathrm{dl}(-0.23 \mathrm{mmol} / \mathrm{l}),-33.52$ to $-13.90)$ overall (table 2 ) and separately in pre-dialysis patients (15 comparisons, 836 patients; $-28.71 \mathrm{mg} / \mathrm{dl}$ $(-0.28 \mathrm{mmol} / \mathrm{l}),-48.55$ to -8.87$)$ and transplant patients (11 comparisons, 2955 patients; -25.24 $\mathrm{mg} / \mathrm{dl}(-0.25 \mathrm{mmol} / \mathrm{l}),-33.49$ to -16.99$)$ but not in dialysis patients (13 comparisons, 1778 patients; $-22.67 \mathrm{mg} / \mathrm{dl}(-0.22 \mathrm{mmol} / \mathrm{l}),-46.80$ to 1.46$)$.

\section{Proteinuria and creatinine clearance}

We found a significant reduction in 24 hour urinary protein excretion $(\mathrm{g} / 24 \mathrm{~h})$ in chronic kidney disease (pre-dialysis) patients receiving statins compared with placebo $(6$ randomised controlled trials, 311 patients; weighted mean difference $-0.73 \mathrm{~g} / 24$ hour, -0.95 to -0.52 ), with significant heterogeneity in this analysis (heterogeneity $\chi^{2}=12.07, \mathrm{I}^{2}=58.6 \%$ ) (table 2). Creatinine clearance (either in $\mathrm{ml} / \mathrm{min}$ or $\mathrm{ml} / \mathrm{min} / 1.73 \mathrm{~m}^{2}$ ) did not change with statins in comparison with placebo (11 randomised controlled trials, 548 patients; weighted mean difference $1.48 \mathrm{ml} / \mathrm{min}(0.024 \mathrm{ml} / \mathrm{s})$, -2.32 to 5.28$)$.

Effect of statins on patient level end points in chronic kidney disease

All cause and cardiovascular mortality and non-fatal cardiovascular events

We found no significant reduction in the risk of all cause mortality with statins in chronic kidney disease overall (44 trials, 23665 patients; relative risk 0.92 , $95 \%$ confidence interval 0.82 to 1.03$)$. A significant (approximately 20\%) reduction in risk occurred in predialysis patients (21 trials, 18781 patients; relative risk $0.81,0.74$ to 0.89$)$, largely driven by the pravastatin pooling project, but we found no statistically significant interaction between the separate groups of pre-dialysis, 
Table 1|Characteristics of populations, interventions, and outcomes in included trials

\begin{tabular}{|c|c|c|c|c|c|c|c|c|c|c|}
\hline \multirow[b]{2}{*}{ Study ID } & \multirow[b]{2}{*}{$\begin{array}{l}\text { Intervention } \\
\text { (statin) }\end{array}$} & \multirow{2}{*}{$\begin{array}{l}\text { Dose } \\
\text { (mg/ } \\
\text { day) }\end{array}$} & \multirow{2}{*}{$\begin{array}{c}\text { Study } \\
\text { duration } \\
\text { (months) }\end{array}$} & \multirow[b]{2}{*}{$\begin{array}{c}\text { No of } \\
\text { patients }\end{array}$} & \multirow[b]{2}{*}{$\begin{array}{l}\text { Mean (SD) baseline } \\
\text { cholesterol (mg/dl) }\end{array}$} & \multirow{2}{*}{$\begin{array}{c}\text { Mean (SD) baseline } \\
\text { glomerular filtration rate } \\
(\mathrm{ml} / \mathrm{min} / 1.73 \mathrm{~m} 2)\end{array}$} & \multicolumn{4}{|c|}{ Outcomes } \\
\hline & & & & & & & $\begin{array}{l}\text { Plasma } \\
\text { lipids }\end{array}$ & $\begin{array}{l}\text { Mortality, CV events } \\
\text { (fatal, non-fatal) }\end{array}$ & Renal & $\begin{array}{l}\text { Side } \\
\text { effects }\end{array}$ \\
\hline \multicolumn{11}{|l|}{ Pre-dialysis } \\
\hline Yutaka 99 w12* & Pravastatin & 20 & 6 & 57 & $247.5(5.3)$ & $64.4(5.4)$ & Yes & No & Yes & No \\
\hline Zhang $95^{\text {w15 }}$ & Pravastatin & 20 & 3 & 20 & NA & NA & Yes & Yes & No & Yes \\
\hline Lee $02^{\text {w22 }}$ & Pravastatin & 10 & 6 & 63 & $210(23)$ & $85(16)$ & Yes & Yes & Yes & No \\
\hline Lee $05^{\text {w16 }}$ & Pravastatin & 10 & 6 & 82 & $208(23)$ & 90 (19) & Yes & Yes & Yes & Yes \\
\hline PPP $04^{\text {w10 }}$ & Pravastatin & 40 & 60 & 16824 & NA & $30.0-89.9$ & Yes & Yes & No & No \\
\hline PREVEND IT $04^{\mathrm{w} 25}$ & Pravastatin & 40 & 48 & 864 & $193.3(33.3)$ & NA & Yes & Yes & Yes & Yes \\
\hline Gheith $02^{\text {w2* }}$ & Fluvastatin & 20 & 12 & 43 & NA & $98.8(37)$ & Yes & Yes & Yes & Yes \\
\hline Lemos $05^{\mathrm{w} 26}$ & Fluvastatin & 80 & $36-48$ & 310 & $200.0(33.0)$ & $47.0(7.0)$ & Yes & Yes & No & No \\
\hline Buemi $00^{\text {w20 }}$ & Fluvastatin & 40 & 6 & 21 & NA & NA & Yes & Yes & Yes & No \\
\hline Yasuda $04^{\text {w19 }}$ & Fluvastatin & 20 & 12 & 80 & $265.3(5.7)$ & $59(5)$ & Yes & Yes & Yes & No \\
\hline $\operatorname{Lam} 95^{\mathrm{w} 4}$ & Lovastatin & 20 & 24 & 34 & $210.0(3.3)$ & $83.1(9.5)$ & Yes & Yes & Yes & No \\
\hline Hommel $92^{\text {w3 }}$ & Simvastatin & 10 & 3 & 26 & $226.6(33.3)$ & $64.0(30.0)$ & Yes & Yes & Yes & Yes \\
\hline Thomas $93^{\mathrm{w} 9}$ & Simvastatin & 10 & 6 & 30 & $315.3(79.0)$ & $76.5(36.5)$ & Yes & Yes & No & Yes \\
\hline Nielsen $93^{\text {w6 }}$ & Simvastatin & $10-20$ & 9 & 18 & $223.3(10.0)$ & $96.6(8.0)$ & Yes & Yes & Yes & No \\
\hline Rayner 95w7 & Simvastatin & $10-40$ & 24 & 17 & NA & $84.3(10.5)$ & Yes & Yes & Yes & Yes \\
\hline Tonolo 97 ${ }^{\mathrm{w} 11 \star}$ & Simvastatin & 20 & 12 & 19 & $223.3(10.0)$ & $97.0(7.0)$ & Yes & Yes & Yes & No \\
\hline HARP $05^{\text {w13 }}$ & Simvastatin & 20 & 12 & 241 & NA & $62.0(55.4)$ & Yes & No & No & Yes \\
\hline Van dijk $01^{\text {w14* }}$ & Simvastatin & 40 & 2 & 20 & NA & $>50.0$ & Yes & Yes & Yes & Yes \\
\hline Scanferla $91^{\text {w18 }}$ & Simvastatin & 10 & 12 & 24 & $263(22)$ & 41 & Yes & Yes & Yes & No \\
\hline Fried $01^{\mathrm{w} 17}$ & Simvastatin & $10-20$ & 24 & 36 & $191.8(21.5)$ & NA & Yes & Yes & Yes & No \\
\hline HPS $03^{\text {w24 }}$ & Simvastatin & 40 & 57 & 5963 & NA & NA & & Yes & No & No \\
\hline Stegmayr $05^{\mathrm{w} 8}$ & Atorvastatin & 10 & 24 & 14 & NA & $<30.0$ & Yes & Yes & No & Yes \\
\hline DallaNora $03^{\text {w21 }}$ & Atorvastatin & 10 & 12 & 24 & $236(53)$ & NA & Yes & Yes & Yes & No \\
\hline Bianchi 03w1* & Atorvastatin & 40 & 12 & 56 & $306.0(3.0)$ & 56.0 (1.9) & Yes & Yes & Yes & No \\
\hline Nakamura $02^{\text {w5* }}$ & Cerivastatin & 0.2 & 6 & 40 & $276.0(58.0)$ & $104(10)$ & Yes & Yes & Yes & No \\
\hline Verma $05^{\mathrm{w} 23}$ & Rosuvastatin & 10 & 5 & 91 & $224(61)$ & $42.3(11.1)$ & Yes & Yes & No & Yes \\
\hline \multicolumn{11}{|l|}{ Dialysis } \\
\hline Perfect $97^{\text {w31 }}$ & Simvastatin & $5-20$ & 6 & 107 & $210.0(3.3)$ & NA & Yes & Yes & No & Yes \\
\hline Saltissi $02^{\text {w32 }}$ & Simvastatin & 20 & 6 & 55 & $234.0(44.0)$ & NA & Yes & No & No & Yes \\
\hline HARP $05^{\text {w13 }}$ & Simvastatin & 20 & 12 & 73 & $159.3(40.6)$ & NA & Yes & No & No & Yes \\
\hline Chang $02^{\text {w34 }}$ & Simvastatin & 20 & 2 & 62 & $232(25)$ & NA & Yes & Yes & No & No \\
\hline Diepeveen $02^{\text {w27 }}$ & Atorvastatin & 10 & 3 & 37 & $143.3(34.6)$ & NA & Yes & Yes & No & Yes \\
\hline Harris $02^{\text {w29 }}$ & Atorvastatin & $10-40$ & 4 & 130 & $219.3(24.0)$ & NA & Yes & Yes & No & Yes \\
\hline Lins $04^{\text {w30 }}$ & Atorvastatin & 10 & 3 & 42 & $235.0(37.0)$ & NA & Yes & Yes & No & Yes \\
\hline Stegmayr $05^{\mathrm{w} 8}$ & Atorvastatin & 10 & 24 & 89 & NA & NA & Yes & Yes & No & Yes \\
\hline $4 \mathrm{D}$ trial $05^{13}$ & Atorvastatin & 20 & 48 & 1255 & $218.0(43.0)$ & NA & Yes & Yes & No & Yes \\
\hline Dornbrook $05^{\text {w33 }}$ & Atorvastatin & 10 & 5 & 19 & $194(33)$ & NA & Yes & Yes & No & \\
\hline Ichihara $02^{\text {w28 }}$ & Fluvastatin & 20 & 6 & 22 & $168(13)$ & NA & Yes & Yes & No & No \\
\hline \multicolumn{11}{|l|}{ Transplant } \\
\hline Cofan $02^{\text {w48 }}$ & Pravastatin & 20 & 12 & 47 & NA & NA & Yes & Yes & No & No \\
\hline Katznelson $96^{\text {w35 }}$ & Pravastatin & 20 & 4 & 48 & $181.9(8.1)$ & NA & Yes & Yes & Yes & Yes \\
\hline Tuncer $00^{\text {w36 }}$ & Pravastatin & 20 & 12 & 57 & NA & NA & Yes & Yes & Yes & Yes \\
\hline Holdaas $01^{\text {w38 }}$ & Fluvastatin & 40 & 3 & 364 & $158.0(4.2)$ & NA & Yes & Yes & Yes & Yes \\
\hline Holdaas $03^{\mathrm{w} 42} \dagger$ & Fluvastatin & $40-80$ & 60 & 2102 & $216.6(36.6)$ & NA & Yes & Yes & No & Yes \\
\hline Kosch $03^{\text {w46 }} \ddagger$ & Fluvastatin & 40 & 36 & 26 & $277.0(6.0)$ & NA & Yes & Yes & No & Yes \\
\hline Castelao $93^{\text {w49 }}$ & Lovastatin & 20 & 32 & 6 & $263.5(30.3)$ & NA & Yes & No & No & Yes \\
\hline Paczek $97^{\text {w47 }}$ & Lovastatin & $10-20$ & 6 & 33 & NA & NA & Yes & Yes & No & No \\
\hline Sharma $01^{\text {w39 }}$ & Lovastatin & 20 & 3 & 65 & $161.8(9.1)$ & NA & Yes & Yes & Yes & Yes \\
\hline Arnadottir $93^{44} \S$ & Simvastatin & 10 & 4 & 40 & $270.0(46.6)$ & NA & Yes & Yes & No & Yes \\
\hline Hernandez $93^{\text {w45 }}$ & Simvastatin & 5 & 2 & 22 & $253.0(50.0)$ & NA & Yes & Yes & No & Yes \\
\hline Kasiske $01^{\text {w37 }}$ & Simvastatin & 10 & 3 & 105 & NA & NA & Yes & Yes & Yes & Yes \\
\hline Lepre $99^{\text {w43 }}$ & Simvastatin & $5-10$ & 3 & 49 & $240.0(30.0)$ & NA & Yes & Yes & No & Yes \\
\hline Santos $01^{\text {w41 }}$ & Simvastatin & 10 & 6 & 62 & $161.8(9.1)$ & $63.4(17.6)$ & Yes & Yes & No & Yes \\
\hline Tuncer $00^{\text {w36 }}$ & Simvastatin & 10 & 12 & 57 & NA & NA & Yes & Yes & Yes & Yes \\
\hline HARP $05^{\mathrm{w} 13}$ & Simvastatin & 20 & 12 & 133 & $165.0(32.6)$ & $36.0(32.1)$ & Yes & No & No & Yes \\
\hline Renders $01^{\text {w40 }}$ & Atorvastatin & 10 & 3 & 20 & $245.0(37.0)$ & $1.2(0.6$ & Yes & Yes & No & Yes \\
\hline
\end{tabular}

$\mathrm{CV}=$ cardiovascular; $\mathrm{NA}=$ not available.

*Studies that reported glomerular filtration rate in $\mathrm{ml} / \mathrm{min}$.

†Baseline serum creatinine of statin group $=1.67(0.61$

$\ddagger$ Baseline serum creatinine of statin group $=1.20(0.10$.

$\S$ Baseline serum creatinine of statin group $=1.42(0.04$ 
dialysis, and transplant patients (heterogeneity $\chi^{2}=16.05, \mathrm{I}^{2}=25.2 \%, \mathrm{P}=0.12$ for interaction), suggesting that stage of chronic kidney disease is not a proved effect modifier, which makes the overall estimate of effect the most robust (fig 2).

We found a significant (approximately 20\%) reduction in the risk of cardiovascular mortality (43 trials, 23266 patients; relative risk $0.81,0.73$ to 0.90 ), with no statistically significant heterogeneity (heterogeneity $\chi^{2}=8.45, \mathrm{I}^{2}=0 \%, \mathrm{P}=0.23$ for interaction) (fig 3) and no apparent difference in treatment effect across predialysis, dialysis, and transplant populations. Compared with placebo, statins also significantly decreased the risk of non-fatal cardiovascular events by $20 \%(8$ trials, 22863 patients, relative risk $0.78,0.73$ to 0.84 ), with no significant heterogeneity among the studies (heterogeneity $\chi^{2}=7.68, \mathrm{I}^{2}=8.9 \%$ ) (fig 4 ). This effect was consistent across pre-dialysis and dialysis patients, with no significant interaction $(\mathrm{P}=0.18$ for interaction).

\section{End stage renal disease and allograft rejection}

We found no trials reporting end stage renal disease or doubling of creatinine as an outcome. No significant reduction occurred in the risk of acute allograft rejection with statins used for three months in the immediate post-transplant period compared with placebo (5 trials, 639 patients; relative risk $0.73,0.49$ to 1.10 ) (fig 5). We found a significant heterogeneity among these trials (heterogeneity $\chi^{2}=8.97, \mathrm{I}^{2}=55.4 \%$ ), which could be explained by the different sample sizes in the included studies, the different subsets of patients included (cadaveric and living related transplant recipients), and the different immunosuppressive regimens used. These studies did not report on the effect of statins on chronic allograft nephropathy.

\section{Adverse effects}

We found no significant increase in the risk of abnormalities in liver function tests (26 trials, 6726 patients) or raised creatinine phosphokinase concentrations (risk of rhabdomyolysis) (29 trials, 6829 patients; relative risk $1.50,0.86$ to 2.59 ; heterogeneity $\chi^{2}=7.73, \mathrm{I}^{2}=0 \%$ ) for statins compared with placebo. We also found no significant difference in the risk of withdrawal from the study owing to adverse events for statins compared with placebo (20 trials, 4887 patients; relative risk $1.03,0.84$ to 1.25 ; heterogeneity $\chi^{2}=17.79$, $\mathrm{I}^{2}=10 \%$ ) (fig 6).

\section{Analysis of heterogeneity}

Meta-regression of heterogeneity was possible only for the outcome of total cholesterol and low density lipoprotein cholesterol at end of treatment, as all other outcomes were reported in too few trials for analysis to be robust. On univariate meta-regression, the type of statin (38.42\%), baseline cholesterol concentrations $(60.73 \%)$, and allocation concealment $(13.80 \%)$ seemed to be responsible for most of the heterogeneity in the effect of statins on total cholesterol concentrations; statin type (10.99\%), age (19.39\%), baseline cholesterol concentrations (34.43\%), and allocation concealment $(20.05 \%)$ were the major causes of heterogeneity in the analysis of effect of statins on low density lipoprotein cholesterol concentrations (table 3). The observed significant heterogeneity by type of statin may be largely explained by the single trial of cerivastatin. ${ }^{\mathrm{w} 5}$ When we excluded this trial from the analyses, heterogeneity became non-significant. Trials with adequate concealment of allocation had more precise estimates (total cholesterol: weighted mean difference $-38.16 \mathrm{mg} / \mathrm{dl},-49.59$ to -26.73 ; low density lipoprotein cholesterol: $-36.67 \mathrm{mg} / \mathrm{dl},-48.23$ to -25.10 ), whereas those with inadequate allocation concealment (total cholesterol: $-55.01 \mathrm{mg} / \mathrm{dl},-69.19$ to -40.83 ; low density lipoprotein cholesterol: $-59.93 \mathrm{mg} / \mathrm{dl},-76.31$ to -43.54$)$ or unclear allocation concealment (total cholesterol: $-52.06 \mathrm{mg} / \mathrm{dl},-62.93$ to -41.19 ; low density lipoprotein cholesterol: $-49.44 \mathrm{mg} / \mathrm{dl},-60.64$ to -38.24$)$ tended to suggest greater benefits for the experimental intervention (statin).

Table 4 shows the results of a multivariate metaregression analysis in which we analysed potential sources of heterogeneity in the effects of statins compared with placebo on total cholesterol and low density lipoprotein cholesterol at the end of treatment after accounting for any covariate that was clinically relevant or statistically significant on univariate analysis. For both total cholesterol and low density lipoprotein cholesterol concentrations at the end of treatment, the model including the type of statin, dose of statin, age of participants, allocation concealment,

\begin{tabular}{|c|c|c|c|}
\hline Outcome & No of trials (No of patients) & $\begin{array}{l}\text { Weighted mean difference (95\% } \\
\qquad \mathrm{Cl})\end{array}$ & Heterogeneity ( $12 ; \%)$ \\
\hline Total cholesterol (mg/dl)* & $42(6390)$ & $-42.28(-47.25$ to -37.32$)$ & 94.9 \\
\hline LDL cholesterol $(\mathrm{mg} / \mathrm{dl})^{*}$ & $39(6216)$ & $-43.12(-47.85$ to -38.40$)$ & 94.1 \\
\hline HDL cholesterol (mg/dl)* & $40(5621)$ & $0.41(-0.78$ to 1.60$)$ & 94.4 \\
\hline Triglycerides $(\mathrm{mg} / \mathrm{dl}) \dagger$ & $39(5569)$ & $-23.71(-33.52$ to -13.90$)$ & 89.5 \\
\hline $\begin{array}{l}\text { Glomerular filtration rate }(\mathrm{ml} / \mathrm{min} \text { or } \\
\left.\mathrm{ml} / \mathrm{min} / 1.73 \mathrm{~m}^{2}\right)\end{array}$ & $11(548)$ & $1.48(-2.32$ to 5.28$)$ & 62.0 \\
\hline Urinary protein excretion (g/24 h) & $6(311)$ & $-0.73(-0.95$ to -0.52$)$ & 58.6 \\
\hline
\end{tabular}

$\mathrm{HDL}=$ high density lipoprotein; $L D L=l o w$ density lipoprotein.

*Multiply by 0.0259 to convert to $\mathrm{mmol} / \mathrm{l}$.

†Multiply by 0.01 to convert to $\mathrm{mmol} / \mathrm{l}$. 


\begin{tabular}{|c|c|c|c|c|c|c|c|c|c|c|}
\hline \multirow[b]{2}{*}{ Model } & \multirow[b]{2}{*}{ Covariate } & \multirow[b]{2}{*}{ Classification } & \multicolumn{4}{|c|}{ Total cholesterol at end of treatment $(\mathrm{mg} / \mathrm{dl})$} & \multicolumn{4}{|c|}{ LDL cholesterol at end of treatment $(\mathrm{mg} / \mathrm{dl})$} \\
\hline & & & $\begin{array}{l}\text { No of studies or } \\
\text { subsets }\end{array}$ & $\begin{array}{l}\text { Weighted mean difference* } \\
\qquad(95 \% \mathrm{Cl})\end{array}$ & Pvalue $\dagger$ & $\begin{array}{l}\text { Heterogeneity explained by } \\
\text { covariate (\%) }\end{array}$ & $\begin{array}{l}\text { No of } \\
\text { studies }\end{array}$ & $\begin{array}{l}\text { Weighted mean difference* } \\
\qquad(95 \% \mathrm{Cl})\end{array}$ & Pvalue $\dagger$ & $\begin{array}{l}\text { Heterogeneity explained } \\
\text { by covariate (\%) }\end{array}$ \\
\hline 0 & None & Intercept & 30 & $-47.86(-55.15$ to -40.56$)$ & $<0.01$ & 0.00 & 29 & $-46.64(-54.53$ to -38.75$)$ & $<0.01$ & 0.00 \\
\hline \multirow{3}{*}{1} & \multirow{3}{*}{ Dose } & $0-20 \ddagger$ & 13 & $-45.58(-56.42$ to -34.74$)$ & 0.36 & 2.17 & 12 & $-44.25(-56.69$ to -31.81$)$ & 0.64 & 0.00 \\
\hline & & $20-40 \ddagger$ & 10 & -44.08 to $(-56.82$ to -31.34$)$ & - & - & 10 & $-44.76(-58.55$ to -30.97$)$ & - & - \\
\hline & & $40-80 \ddagger$ & 7 & $-57.37(-72.37$ to -42.37$)$ & - & - & 7 & $-53.58(-69.99$ to -37.17$)$ & - & - \\
\hline $1 \mathrm{a}$ & Dose & Continuous & 30 & $-48.25(-55.22$ to -41.28$)$ & $<0.01$ & 5.76 & 29 & $-37.56(-52.56$ to -22.55$)$ & $<0.01$ & 2.58 \\
\hline \multirow{6}{*}{2} & \multirow{6}{*}{ Type of statin } & Pravastatin & 3 & $-33.15(-38.78$ to -27.52$)$ & $<0.01$ & 38.42 & 3 & $-41.15(-45.99$ to -36.32$)$ & 0.15 & 10.99 \\
\hline & & Fluvastatin & 3 & $-25.66(-37.53$ to -13.80$)$ & - & - & 3 & $-30.87(-42.97$ to -19.47$)$ & - & - \\
\hline & & Lovastatin & 2 & $-42.40(-51.76$ to -33.04$)$ & - & - & 2 & $-46.62(-59.12$ to -26.11$)$ & - & - \\
\hline & & Simvastatin & 14 & $-46.85(-57.49$ to -36.21$)$ & - & - & 13 & $-47.22(-58.68$ to -35.77$)$ & - & - \\
\hline & & Atorvastatin & 7 & $-60.17(-76.31$ to -44.04$)$ & - & - & 7 & $-59.58(-77.18$ to -41.97$)$ & - & - \\
\hline & & Cerivastatin & 1 & $-96.00(-124.27$ to -67.73$)$ & - & - & 1 & $-76.00(-94.96$ to -57.04$)$ & - & - \\
\hline \multirow{3}{*}{3} & \multirow{3}{*}{$\begin{array}{l}\text { Duration } \\
\text { (months) }\end{array}$} & $0-6$ & 20 & $-49.94(-59.24$ to -40.65$)$ & 0.40 & 0.00 & 19 & $-49.88(-59.85$ to -39.91$)$ & 0.26 & 0.39 \\
\hline & & 6-12 & 6 & $-50.36(-66.18$ to -34.54$)$ & - & - & 6 & $-47.86(-64.34$ to -31.39$)$ & - & - \\
\hline & & 112 & 4 & $-35.68(-54.73$ to -16.62$)$ & - & - & 4 & $-30.95(-51.50$ to -10.40$)$ & - & - \\
\hline $3 a$ & $\begin{array}{l}\text { Duration } \\
\text { (months) }\end{array}$ & Continuous & 30 & $-48.19(-55.47$ to -40.92$)$ & $<0.01$ & 1.33 & 29 & $-46.95(-54.78$ to -39.11$)$ & $<0.01$ & 2.02 \\
\hline \multirow{4}{*}{4} & \multirow{4}{*}{ Age§ } & Not reported & 4 & $-43.53(-63.49$ to -23.57$)$ & 0.01 & 8.32 & 4 & $-45.37(-65.37$ to -25.37$)$ & 0.04 & 19.39 \\
\hline & & $\ll 49$ (first third) & 9 & $-50.41(-62.83$ to -38.00$)$ & - & - & 8 & $-54.66(-67.94$ to -41.38$)$ & - & - \\
\hline & & $\begin{array}{l}\text { 49-54 (second } \\
\text { third) }\end{array}$ & 9 & $-35.85(-49.01$ to -22.69$)$ & - & - & 9 & $-30.31(-43.76$ to -16.86$)$ & - & - \\
\hline & & $>54$ (third third) & 8 & $-59.45(-73.13$ to -45.77$)$ & - & - & 8 & $-55.10(-68.76$ to -41.44$)$ & - & - \\
\hline $4 a$ & Age & Continuous & 26 & $-48.72(-57.12$ to -40.32$)$ & $<0.01$ & 0.00 & 25 & $-47.02(-56.15$ to -37.90$)$ & $<0.01$ & 0.00 \\
\hline \multirow{4}{*}{5} & \multirow{4}{*}{ Hypertension (\%)- } & Not reported & 18 & $-45.33(-55.13$ to -35.53$)$ & 0.84 & 0.00 & 17 & $-43.24(-53.79$ to -32.70$)$ & 0.68 & 0.00 \\
\hline & & $0-20 \%$ & 5 & $-50.07(-67.77$ to -32.37$)$ & - & - & 5 & $-47.12(-65.73$ to -28.51$)$ & - & - \\
\hline & & $20-60 \%$ & 5 & $-51.47(-69.74$ to -33.20$)$ & - & - & 5 & $-52.93(-72.15$ to -33.72$)$ & - & - \\
\hline & & $60-100 \%$ & 2 & $-58.13(-90.33$ to -25.93$)$ & - & - & 2 & $-61.32(-95.56$ to -27.09$)$ & - & - \\
\hline \multirow{3}{*}{6} & \multirow{3}{*}{ Diabetes (\%) } & Not reported & 15 & $-49.15(-60.24$ to -38.06$)$ & 0.90 & 0.00 & 15 & $-45.89(-57.51$ to -34.28$)$ & 0.78 & 0.00 \\
\hline & & $\ll 30 \%$ & 9 & $-45.43(-58.61$ to -32.25$)$ & - & - & 8 & $-44.12(-59.18$ to -29.06$)$ & - & - \\
\hline & & $100 \%$ & 6 & $-49.18(-65.59$ to -32.76$)$ & - & - & 6 & $-52.12(-69.87$ to -34.37$)$ & - & - \\
\hline 7 & $\begin{array}{l}\text { Baseline } \\
\text { cholesterolई }\end{array}$ & Continuous & 27 & $-48.46(-54.11$ to -42.81$)$ & $<0.01$ & 60.73 & 26 & $-47.44(-54.67$ to -40.20$)$ & $<0.01$ & 34.43 \\
\hline \multirow{3}{*}{8} & \multirow{3}{*}{$\begin{array}{l}\text { Stage of kidney } \\
\text { disease }\end{array}$} & Pre-dialysis & 10 & $-47.03(-60.25$ to -33.81$)$ & 0.42 & 0.28 & 10 & $-45.37(-59.19$ to -31.55$)$ & 0.55 & 0.00 \\
\hline & & Dialysis & 10 & $-54.23(-66.78$ to -41.67$)$ & - & - & 10 & $-52.44(-66.03$ to -38.86$)$ & - & - \\
\hline & & Transplant & 10 & $-42.59(-54.74$ to -30.45$)$ & - & - & 9 & $-41.72(-55.90$ to -27.55$)$ & - & - \\
\hline \multirow{3}{*}{9} & \multirow{3}{*}{$\begin{array}{l}\text { Allocation } \\
\text { concealment }\end{array}$} & Adequate & 10 & $-38.16(-49.59$ to -26.73$)$ & 0.12 & 13.80 & 10 & $-36.67(-48.23$ to -25.10$)$ & 0.06 & 20.05 \\
\hline & & Inadequate & 7 & $-55.01(-69.19$ to -40.83$)$ & - & - & 6 & $-59.93(-76.31$ to -43.54$)$ & - & - \\
\hline & & Unclear & 13 & $-52.06(-62.93$ to -41.19$)$ & - & - & 13 & $-49.44(-60.64$ to -38.24$)$ & - & - \\
\hline 10 & Year & Continuous & 30 & $-53.65(-72.65$ to -34.65$)$ & $<0.01$ & 0.00 & 29 & $-58.14(-78.06$ to -38.22$)$ & $<0.01$ & 3.88 \\
\hline
\end{tabular}

Variables (including drug related, patient related, and study quality indicators) analysed as categories or as continuous data when applicable.

*Values $<0$ favour statins; values $>$ favour placebo.

TANOVA P value for difference across groups.

SMean baseline value of experimental (statin) and control (placebo) arms of trials; explored with bivariate meta-regression.

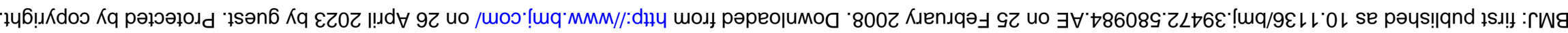


and baseline cholesterol concentrations explained most of the identified heterogeneity in the effect of statins versus placebo. The effect of statins on total cholesterol and low density lipoprotein cholesterol was dose dependent.

\section{DISCUSSION}

\section{Key findings}

Our meta-analysis found that statins are associated with lipid lowering, cardiovascular, and antiproteinuric benefits in chronic kidney disease. They seem to be safe in chronic kidney disease, with respect to the risk of rhabdomyolysis and hepatotoxicity and because limited withdrawals occurred in the treatment group. The risk of cardiovascular events and cardiovascular mortality is reduced by statin treatment in people at different stages of chronic kidney disease (pre-dialysis, dialysis, and transplant), and the magnitude of cardiovascular benefit achieved seems broadly similar in these groups and approximates that of statin treatment in other populations. ${ }^{23}$

Although statins have been conclusively shown to reduce cardiovascular mortality and all cause mortality in the general population, ${ }^{8-10}$ considerable uncertainty

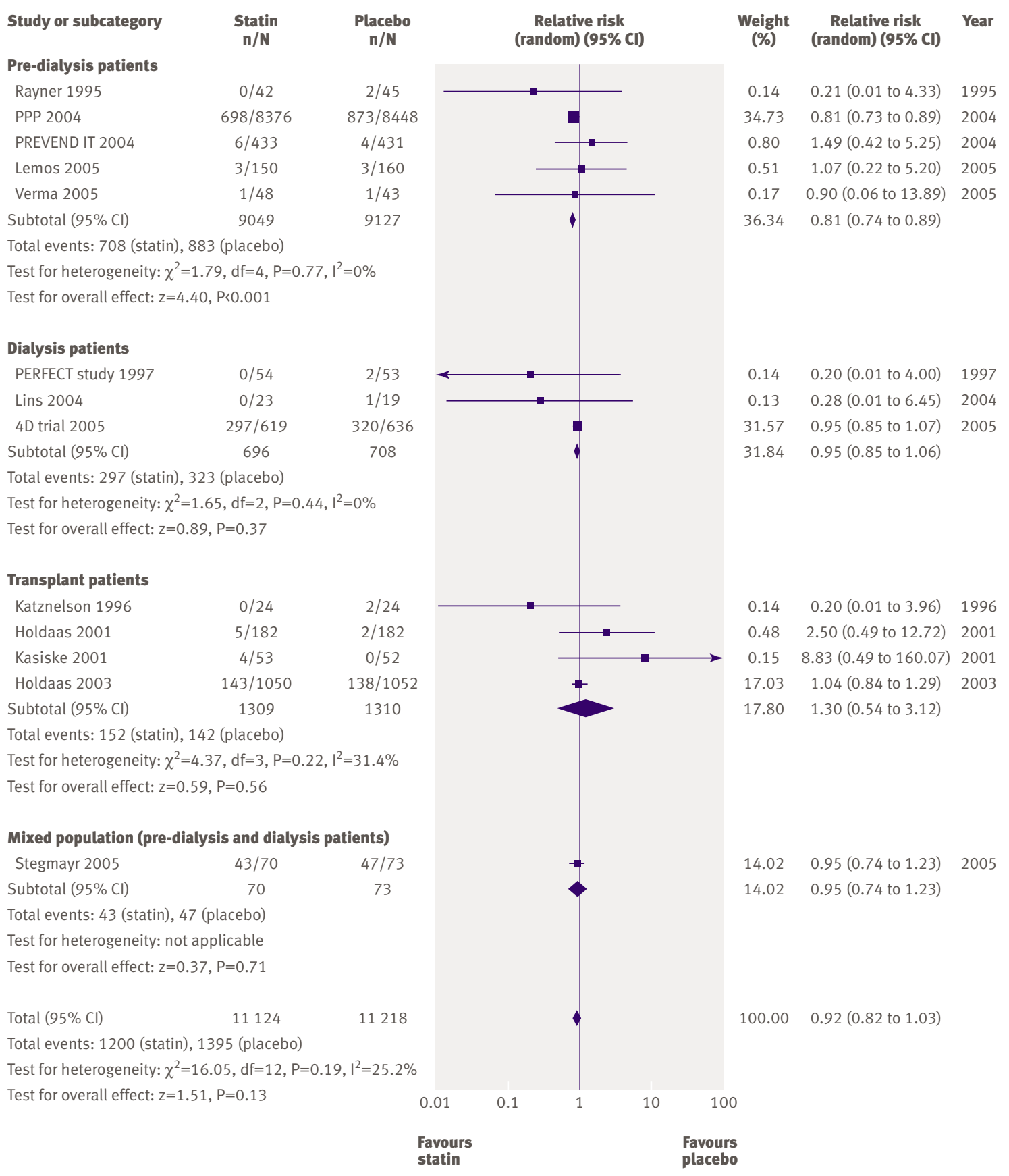

Fig 2 | Effect of statins compared with placebo or no treatment on all cause mortality in pre-dialysis, dialysis, and transplant patients. Almost all studies reported mortality data, but no events were detected in many studies; only studies in which events were detected are included in the plot 
has surrounded the generalisability of the findings of these trials to people with chronic kidney disease. Specifically, the association between lipid abnormalities and cardiovascular outcomes is less clear in dialysis patients; many observational studies have reported significantly higher mortality with lower cholesterol concentrations. ${ }^{11}$ Moreover, concentrations of total cholesterol and low density lipoprotein cholesterol in dialysis patients are actually lower than those in people who are not on dialysis and those who do not have chronic kidney disease, although such observations may be attributable to concomitant malnutrition. ${ }^{24}$ Finally, only about one quarter of cardiovascular mortality in dialysis patients seems to be convincingly attributable to acute myocardial infarction and ischaemic stroke (and therefore potentially modifiable by statins), whereas the other common causes (such as arrhythmias or heart failure) may be less amenable to cholesterol lowering.

Our findings support suggestions that the inverse relations identified in the observational studies can be explained by reverse causality, whereby ill health and poor nutrition separately caused both lower cholesterol concentrations and a higher risk of death. The results support the use of statins in people with chronic kidney disease who have established occlusive coronary disease or cerebrovascular disease or are at particularly high risk of these cardiovascular events.

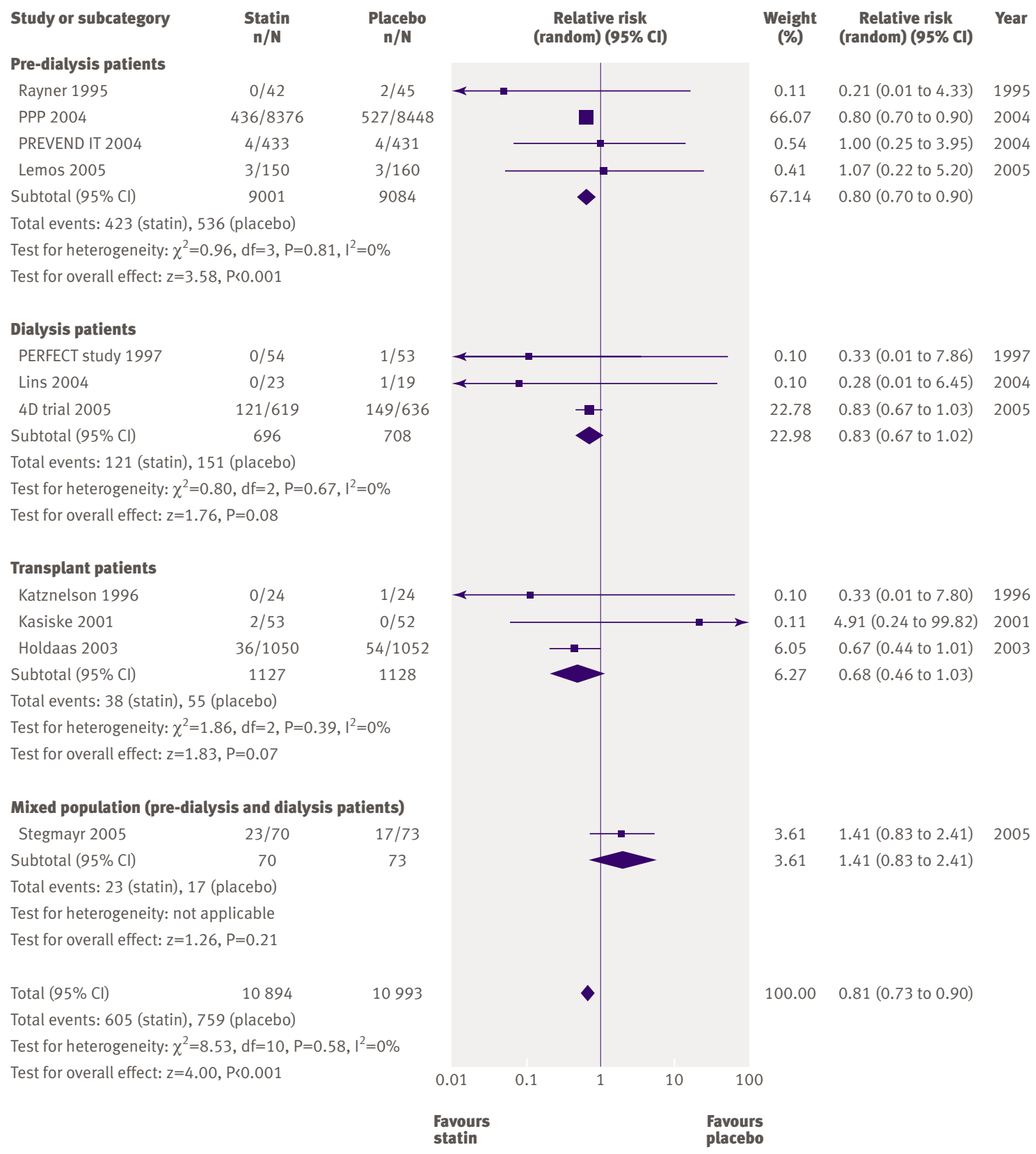

Fig 3 Effect of statins compared with placebo or no treatment on cardiovascular mortality in pre-dialysis, dialysis, and transplant patients. Only studies with at least one event are included in the plot 
That the relative benefits of statins in patients with known coronary heart disease are similar to those in people with mild renal impairment and people with well preserved renal function is plausible - that is, mild renal impairment should not prevent these patients from receiving a statin. Controversy arises when patients have established (stages 3-5) chronic kidney disease and have not yet had a vascular event.

In our systematic review, data on major clinical end points were available from relatively few studies. Although we identified no heterogeneity in the results of the analyses of effect on outcome, the small number of participating studies with substantial numbers of these end points meant that statistical power to detect such differences was suboptimal. That important differences exist in the effects of statins among people with different degrees of chronic kidney disease remains possible. Secondly, the magnitude of the effect on the major clinical end points observed in the $4 \mathrm{D}$ trial, which included patients with the most severe forms of chronic kidney disease (that is, receiving dialysis), was somewhat less than that seen in trials that included participants with better kidney function (all cause mortality: relative risk $0.95,0.85$ to 1.07 ), so that important differences in the balance of risks and benefits may exist for this group. ${ }^{13}$ We should underline that although the $4 \mathrm{D}$ study is generally interpreted as a negative trial, its results are broadly in line with expectations from other trials, except for the findings on stroke. Thirdly, a substantial proportion of the participants in the studies included in this meta-analysis had established occlusive arterial disease and may therefore benefit more than people without such disease (primary prevention), although a recent review

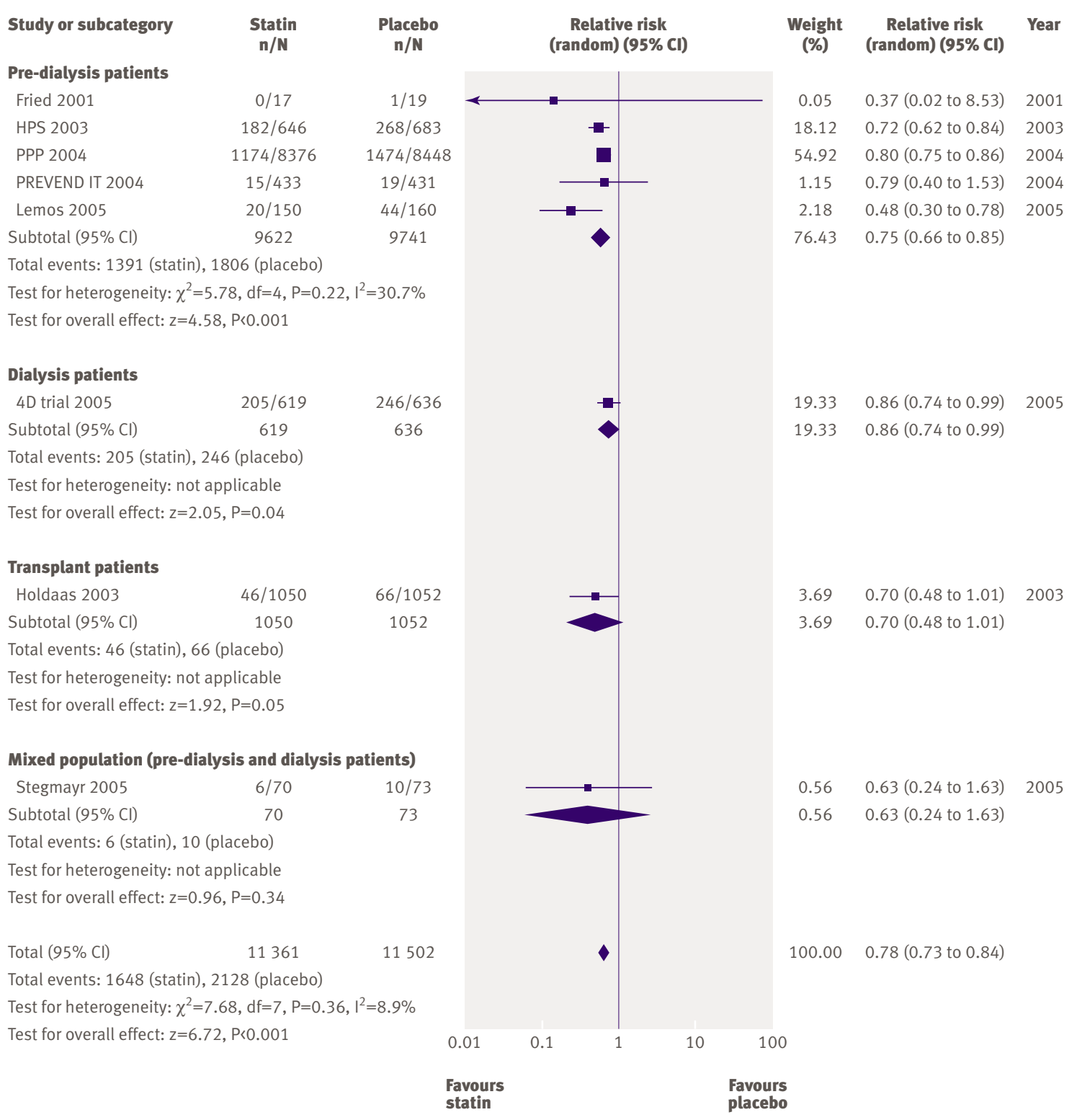

Fig 4 Effect of statins compared with placebo or no treatment on cardiovascular events in pre-dialysis, dialysis, and transplant patients. Only studies with at least one event are included in the plot 


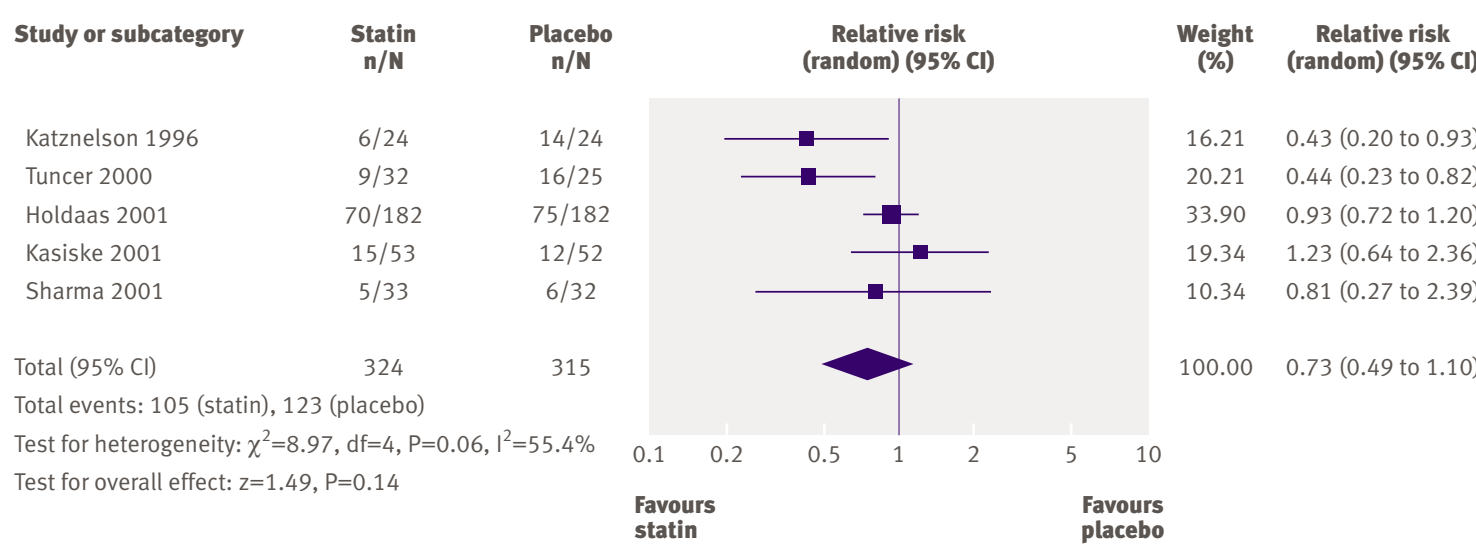

Fig 5 | Effect of statins compared with placebo or no treatment on acute allograft rejection in renal transplant recipients

of statin treatment in diabetes found similar reductions in risk for both primary and secondary prevention. ${ }^{25}$ Finally, this review did not show a significant beneficial effect on all cause mortality. This may be due to a type II statistical error or it may reflect the fact that typical occlusive atherosclerotic diseases (such as myocardial infarction and ischaemic stroke) are responsible for a minority of deaths in people with chronic kidney disease. ${ }^{26}$

Taken together, our findings provide support for the widespread use of statins for the prevention of cardiovascular disease in people with chronic kidney disease who are at high cardiovascular risk (such as those who have established coronary artery disease or ischaemic cerebrovascular disease), but the effects of treatment in people at lower absolute risk and the effects on total mortality remain to be defined. On epidemiological grounds, these lower risk populations are likely to receive less benefit - that is, although effect size may be the same in people who are at lower risk for events, the lower absolute risk means that fewer events are prevented for the same number of patients treated. This may influence decisions by doctors or funding authorities on the use of statins in low risk populations. The ongoing trials will provide crucial additional data in this regard. ${ }^{2728}$ The beneficial effect of statins on the risk of subsequent cardiovascular events in chronic kidney disease is consistent with the fact that the changes in lipid concentrations produced by statins are similar in this group.

Dyslipidaemia is common in chronic kidney disease; some people show elevated low density lipoprotein cholesterol values, whereas many others show a nontraditional lipoprotein pattern characterised by normal or reduced low density lipoprotein cholesterol concentrations, reduced high density lipoprotein concentrations, high triglyceride concentrations, increased apolipoprotein B concentrations, elevated small low density lipoprotein particles, and higher lipoprotein remnants. ${ }^{2930}$ The type and magnitude of the effect of statins on lipid profiles in patients with chronic kidney disease in this review were similar to those described in previous meta-analyses of lipid lowering trials in chronic kidney disease and dialysis patients, ${ }^{31}{ }^{32}$ as well as in patients without chronic kidney disease. This finding is not unexpected, as dosing of statins in chronic kidney disease and the general population is similar, given that the agents are not excreted by the kidney. ${ }^{334}$

We used meta-regression to identify characteristics of patients, studies, or both associated with modifications of therapeutic effects on end of treatment total cholesterol and low density lipoprotein cholesterol concentrations (hence cardiovascular mortality) and thereby identify possible reasons for differences between studies. The multivariate model that explained most of the heterogeneity in the effect of statins compared with placebo was one that included the type of statin (largely explained by a single trial of cerivastatin), dose of statin, patient's age, baseline cholesterol concentration, and allocation concealment. Interestingly, trials with inadequate or unclear allocation concealment had less precise point estimates of effect and tended to overestimate the beneficial effects of statins. This finding again underscores the importance of allocation concealment in minimising the likelihood of bias in randomised controlled trials.

\section{Comparison with other studies}

We also could not clearly confirm evidence of a renoprotective effect of statins in patients with predialysis chronic kidney disease, as indicated by significantly lower values of 24 hour urinary protein excretion and no difference in creatinine clearance in the statin treated groups. The magnitude of the effects was moderate, with an overall reduction in proteinuria of $0.73 \mathrm{~g} /$ day but with no effect on creatinine clearance. The clinical significance of the antiproteinuric effect is less certain, although other reviews have reinforced the renoprotective effects of this class of agents. ${ }^{18}{ }^{19}$ Earlier reviews analysed the proportional reduction in proteinuria, but we analysed the end of treatment values of both treatment and placebo groups. We also identified a trend towards a protective effect of statins on acute renal allograft rejection, but this may have been limited by insufficient statistical power. Outcome reporting bias is a potential problem; less than a quarter of trials 
reported creatinine data and proteinuria, meaning that the remaining studies either did not measure these outcomes or measured them and did not report them. None of the available trials reported end stage renal disease or doubling of serum creatinine as study end points.

The beneficial effect of statins on cardiovascular end points and some evidence of renal benefit seen in our systematic review may be potentially explained by cholesterol dependent effects, cholesterol independent effects, or both. In addition to the well documented association between cholesterol lowering and reduction in cardiovascular risk in non-chronic kidney disease populations, ${ }^{8-10}$ statins may modulate cardiovascular risk by decreasing inflammation, enhancing endothelial function, inhibiting smooth muscle proliferation, exerting direct antithrombotic effects, and stabilising pre-existing atherosclerotic plaque. ${ }^{35-37}$ Statins have also recently been shown to ameliorate vascular calcification, which is an important problem in patients with chronic kidney disease. Similar mechanisms may underpin the beneficial actions of statins on progression of chronic kidney disease, although other cholesterol independent renoprotective actions such as inhibition of renal cell proliferation, antifibrotic effects, suppression of macrophage recruitment, antioxidation, and down regulation of inflammatory cytokines also contribute. ${ }^{3839}$

In addition to considering the potentially beneficial actions of statins on clinical end points in chronic kidney disease, our review provides some important data on the potential harms of statins in this population. Concerns have been expressed about an increased risk of side effects of statins in patients with chronic kidney disease. $^{40}$ In this analysis of more than 6500 such patients, we did not find statins to be associated with an increased incidence of abnormalities in liver function tests or raised serum creatinine phosphokinase concentrations compared with placebo. Although randomised controlled trials and meta-analyses are generally inadequately powered to precisely determine the risks of infrequent serious adverse effects associated with drugs, the inclusion of a large number of patients with chronic kidney disease should provide some reassurance on the relative safety of statins in this group.

\section{Strengths and weaknesses}

A strength of this study is that it is the first to assess cardiovascular, renal, and toxicity outcomes, providing a comprehensive systematic review of the benefits and harms of statins on the basis of a pre-specified detailed published protocol, with rigid inclusion criteria for randomised controlled trials only and a comprehensive search. Two independent investigators extracted data, analysed data, and assessed methodological quality. Furthermore, the possibility of publication bias was minimised by inclusion of both published and unpublished trials. We sought information about unpublished and ongoing randomised controlled trials from authors of the included randomised controlled trials, drug companies, and experts in the field.

The main weakness of this study was the relative paucity of high quality randomised controlled trials. The vast majority of studies evaluated failed to specify whether randomisation allocation was concealed, outcome assessors were blinded, or data were analysed on an intention to treat basis. Many studies were small and often short in duration, and the results of our review were dominated by the results of three major trials: the $4 \mathrm{D}$ trial, PPP, and the ALERT study. ${ }^{13 \mathrm{w} 10 \mathrm{w} 42}$ Moreover, we found evidence of trial heterogeneity in some analyses, including total cholesterol, low density

Table 4 | Multivariate meta-regression analysis of potential sources of heterogeneity on effect of statins versus placebo on total cholesterol and low density lipoprotein cholesterol at end of treatment

\begin{tabular}{|c|c|c|c|c|c|c|}
\hline \multirow[b]{2}{*}{$\begin{array}{l}\text { Covariate being } \\
\text { adjusted for all } \\
\text { others }\end{array}$} & \multicolumn{3}{|c|}{ Total cholesterol } & \multicolumn{3}{|c|}{ Low density lipoprotein cholesterol } \\
\hline & $\begin{array}{c}\text { Adjusted weighted } \\
\text { mean difference* }(95 \% \\
\mathrm{Cl})\end{array}$ & $P$ value & $\begin{array}{c}\text { Explained } \\
\text { variance }(\%)\end{array}$ & $\begin{array}{c}\text { Adjusted weighted } \\
\text { mean difference * }(95 \% \\
\text { CI) }\end{array}$ & $P$ value & $\begin{array}{c}\text { Explained } \\
\text { variance }(\%)\end{array}$ \\
\hline Age & - & 0.07 & 75.26 & - & 0.05 & 37.33 \\
\hline Baseline cholesterol & - & $<0.01$ & - & - & 0.04 & - \\
\hline Dose & - & 0.42 & - & - & 0.39 & - \\
\hline T: pravastatin & $\begin{array}{c}-37.44(-56.28 \text { to } \\
-18.60)\end{array}$ & - & - & $\begin{array}{c}-40.17(-68.67 \text { to } \\
-11.67)\end{array}$ & - & - \\
\hline T: fluvastatin & $\begin{array}{c}-31.52(-45.47 \text { to } \\
-17.57)\end{array}$ & - & - & $-32.35(-54.80$ to -9.90$)$ & - & - \\
\hline $\mathrm{T}$ : lovastatin & $\begin{array}{c}-51.91(-70.81 \text { to } \\
-33.02)\end{array}$ & - & - & $-42.58(-84.63$ to -1.54$)$ & - & - \\
\hline T: simvastatin & $\begin{array}{c}-50.37(-60.73 \text { to } \\
-40.01)\end{array}$ & - & - & $\begin{array}{c}-49.65(-63.79 \text { to } \\
-35.50)\end{array}$ & - & - \\
\hline T: atorvastatin & $\begin{array}{c}-53.82(-71.95 \text { to } \\
-35.70\end{array}$ & 0.07 & - & $\begin{array}{c}-55.14(-80.28 \text { to } \\
-30.00)\end{array}$ & 0.79 & - \\
\hline T: cerivastatin & $\begin{array}{c}-73.92(-111.77 \text { to } \\
-36.07)\end{array}$ & - & - & $-52.04(-96.03$ to -8.04$)$ & - & - \\
\hline
\end{tabular}

T=type of statin.

*Values $<0$ favour statins; values $>0$ favour placebo.

†Explained variance $=100 \times$ (between trial variance in empty model-between trial variance with covariate)/between trial variance in empty model. 


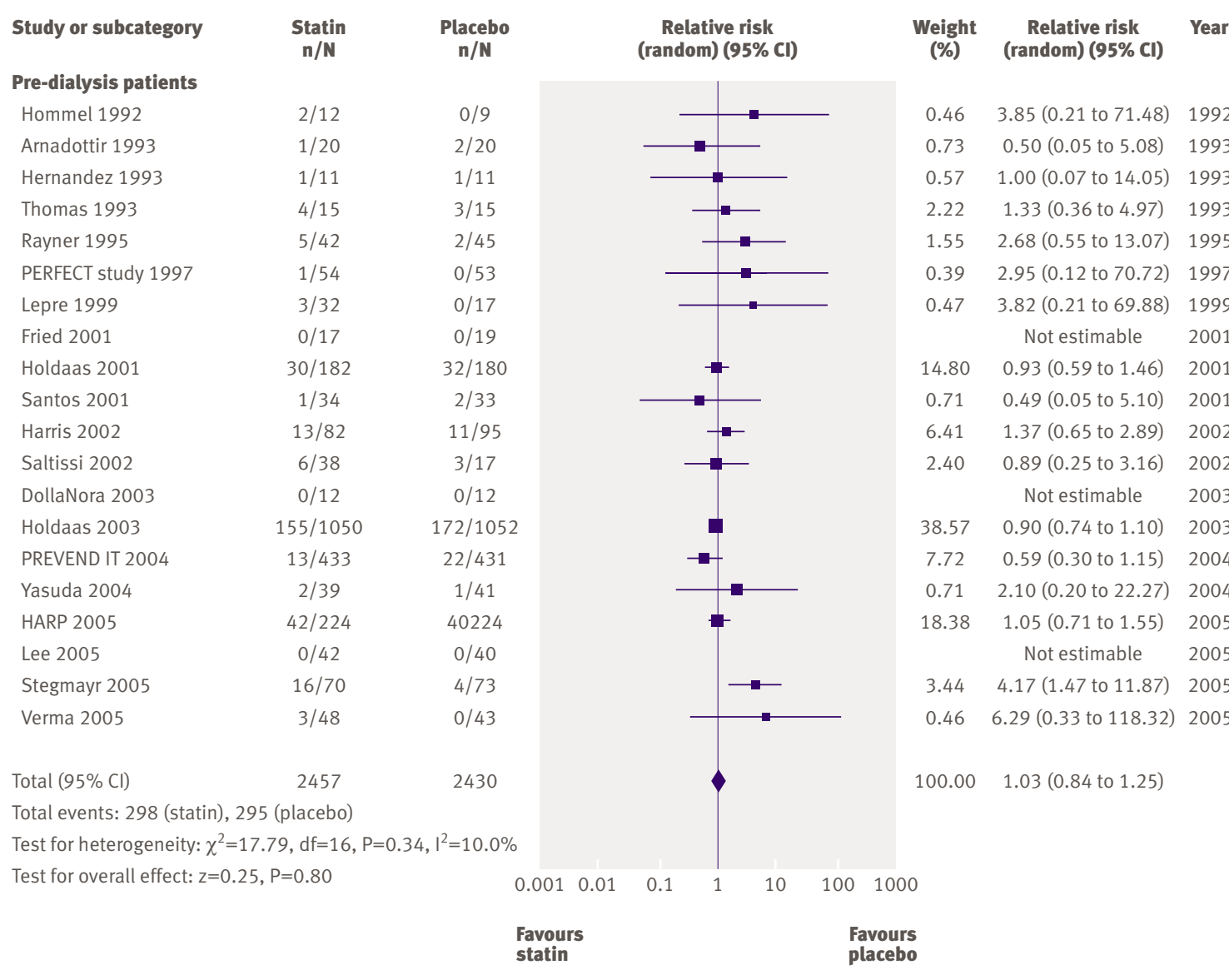

Fig 6 | Withdrawal rates for statins compared with placebo in pre-dialysis, dialysis, and transplant patients. Only studies with at least one withdrawal are included in the plot

lipoprotein cholesterol, triglycerides, creatinine clearance, and acute allograft rejection. As meta-analysis assumes that a mean value estimating the effects of an intervention can be determined by combining similar trials, how to handle summary data when significant heterogeneity exists is not clear. However, we have not been able to show any significant interaction in any analysis in which cumulative estimates were provided, and strong agreement exists between point estimates for individual outcomes in the separate subgroups of pre-dialysis, dialysis, and transplant patients.

\section{Future research and ongoing trials}

Our analysis confirmed the role of statins in secondary prevention in chronic kidney disease patients. Trials of primary prevention with statins are ongoing in people with greater degrees of chronic kidney disease and lower levels of cardiovascular risk (study of heart and renal protection (SHARP) and a study to evaluate the use of rosuvastatin in subjects on regular hemodialysis: an assessment of survival and cardiovascular events (AURORA)). ${ }^{2627}$ The SHARP trial has randomised more than 9000 patients $(6000$ pre-dialysis, 2540 haemodialysis, 490 peritoneal dialysis) to the combination of simvastatin and the cholesterol absorption inhibitor ezetimibe versus placebo and statin versus placebo. The AURORA trial has randomised 2750 haemodialysis patients to rosuvastatin versus placebo. Their combined results, which will involve large numbers of vascular and non-vascular deaths, will help to resolve the question of whether higher concentrations of low density lipoprotein cholesterol are a cause of vascular disease in patients with chronic kidney disease.

\section{Conclusions}

These results suggest that statin treatment is safe and reduces the risk of major cardiovascular events in patients with chronic kidney disease (with cardiovascular disease) in a similar fashion to that seen in trials of statins in non-chronic kidney disease populations. These agents may have antiproteinuric effects, although the clinical significance of these benefits remains uncertain. We did not show an effect on all cause mortality, but this may reflect inadequate statistical power and the fact that, in general, populations with stages 3-5 chronic kidney disease are largely understudied. Ongoing randomised controlled trials in chronic kidney disease patients (SHARP and AURORA) should help to clarify the role of statins in primary prevention and whether the postulated differences in response to statin treatment in chronic kidney disease are real. 


\section{WHAT IS ALREADY KNOWN ON THIS TOPIC}

Patients with chronic kidney disease are at increased risk of cardiovascular disease

Statins reduce cardiovascular mortality and all cause mortality in the general population

The role of statins in chronic kidney disease is controversial

\section{WHAT THIS STUDY ADDS}

Statins reduce cardiovascular deaths in patients with chronic kidney disease by a similar rate to that seen in the general population

The efficacy of statins in reducing all cause mortality in kidney disease patients and their role in primary prevention need to be established in ongoing trials

Statins are safe as regards major side effects such as hepatotoxicity, rhabdomyolysis, and treatment withdrawal
11 Kalantar-Zadeh K, Block G, Humphreys MH, Kopple JD. Reverse epidemiology of cardiovascular risk factors in maintenance dialysis patients. Kidney Int 2003;63:793-808.

12 Seliger SL, Weiss NS, Gillen DL, Kestenbaum B, Ball A, Sherrard DJ, et al. HMG-CoA reductase inhibitors are associated with reduced mortality in end stage renal disease patients. Kidney Int 2002;61:297-304.

13 Wanner C, Krane V, Marz W, Olschewski M, Mann JF, Ruf G, et al. Atorvastatin in patients with type 2 diabetes mellitus undergoing hemodialysis. N Engl J Med 2005;353:238-48.

14 K/DOQI Group. Treating dyslipidemias. Am J Kid Dis 2003;41:S39-58.

15 EBPG Expert Group on Renal Transplantation. European best practice guidelines for renal transplantation. Section IV: long-term management of the transplant recipient. IV.5.3. Cardiovascular risks: hyperlipidaemia. Nephrol Dial Transplant 2002;17(suppl 4):26-8.

16 Renal Association. Clinical practice guidelines. Module 2: complications of CKD disease. Section 1: cardiovascular disease. 2007. www.renal.org/guidelines/module2.html\#Anchor-Summary49575.

17 Walker R. Lipid lowering in patients with chronic kidney disease. (CAR guidelines-Caring for Australasians with Renal Impairment). 2005. www.cari.org.au/Lipid\%20Lowering\%20Therapy.pdf.

We acknowledge the contribution of authors (C Wanner, C Baigent, H Holdaas, M Tonnelli, B G Stegmayr, RL Lins, M E Thomas, S H Diepeveen, A Zhang, M VanDijk, K P Harris, H Hernandez, D Saltissi, C Kosch, and T Nakamura) who provided data about their trials on request. We thank $C$ Baigent and $A$ Webster for their intellectual contribution to the manuscript We also thank Catherine Clase and Martin Landray for critical review of this manuscript. We thank the Cochrane Renal Group staff and search coordinators for their assistance with the search process. This paper has been presented in part as an abstract at the Annual American Society of Nephrology meeting at St Louis, USA, in November 2004 and Philadelphia, USA, in November 2005.

Contributors: GFMS and SDN were equally involved in the concept and design of the review, data extraction, analysis and interpretation of data, and writing the final manuscript. FP was involved in data analysis. AN was involved in writing the final manuscript. DWJ was involved in analysis and interpretation of data and writing the final manuscript. VP was involved in critical revision for intellectual content and interpretation of data and assisted with writing the final manuscript. JCC was involved in concept and design, analysis and interpretation of data, and writing the final manuscript. All authors were involved in final approval of the manuscript to be submitted for publication. GFMS and SDN are the guarantors. Funding: This review was supported in part by the Cochrane Renal Group. Competing interests: None declared.

Ethical approval: Not needed.

Provenance and peer review: Not commissioned; externally peer reviewed.

1 Coresh J, Selvin E, Stevens LA, Manzi J, Kusek JW, Eggers P, et al. Prevalence of chronic kidney disease in the United States. JAMA 2007;298:2038-47.

2 Foley RN, Collins AJ. End-stage renal disease in the United States: an update from the United States renal data system. J Am Soc Nephrol 2007;18:2644-8.

3 Ganesh S, Stack A, Levin N. Association of elevated serum PO(4), Ca × $\mathrm{PO}(4)$, and parathyroid hormone with cardiac mortality risk in chronic hemodialysis patients. J Am Soc Nephrol 2001;12:2131-8.

4 Mallamaci F, Zoccali C, Tripei G, Fermo I, Benedetto FA, Cataliotti A, et al. Hyperhomocysteinemia predicts cardiovascular outcomes in hemodialysis patients. Kidney Int 2002;61:609-14.

5 Jungers P, Massy ZA, Khoa TN, Fumeron C, Labrunie M, Lacour B, et al. Incidence and risk factors of atherosclerotic cardiovascular accidents in predialysis chronic renal failure patients: a prospective study. Nephrol Dial Transplant 1997;12:2597-602.

6 Rossouw JE, Lewis B, Rifkind BM. The value of lowering cholesterol after myocardial infarction. N Engl J Med 1990;323:1112-9.

7 Law MR, Wald NJ, Thompson SG. By how much and how quickly does reduction in serum cholesterol concentration lower risk of ischaemic heart disease? BMJ 1994;308:367-72.

8 Kong SX, Crawford SY, Gandhi SK, Seeger JD, Schumock GT, Lam NP, et al. Efficacy of 3-hydroxy-3-methylglutaryl coenzyme A reductase inhibitors in the treatment of patients with hypercholesterolemia: a meta-analysis of clinical trials. Clin Ther 1997;19:778-97.

9 Hebert PR, Gaziano JM, Chan KS, Hennekens CH. Cholesterol lowering with statin drugs, risk of stroke, and total mortality: an overview of randomized trials. JAMA 1997;278:313-21.

10 Law MR, Wald NJ, Rudnicka AR. Quantifying effect of statins on low density lipoprotein cholesterol, ischaemic heart disease, and stroke: systematic review and meta-analysis. BMJ 2003;326:1423.

outcomes: a meta-analysis. J Am Soc Nephrol 2006:17:2006-16.

19 Douglas K, O'Malley PG, Jackson JL. Meta-analysis: the effect of statin on albuminuria. Ann Intern Med 2006;145:117-24.

20 National Kidney Foundation. K/DOQI clinical practice guidelines for chronic kidney disease: evaluation classification, and stratification. 2000. www.kidney.org/professionals/kdoqi/guidelines_ckd/toc. htm.

21 DerSimonian R, Laird N. Meta-analysis in clinical trials. Contr Clin Trials 1986;7:177-88.

22 Higgins JP, Thompson SG, Deeks JJ, Altman DG. Measuring inconsistency in meta-analyses. BMJ 2003;327:557-60.

23 Randomised trial of cholesterol lowering in 4444 patients with coronary heart disease: the Scandinavian simvastatin survival study (4S). Lancet 1994;344:1383-9.

24 Liu Y, Coresh J, Eustace JA. Association between cholesterol level and mortality in dialysis patients: role of inflammation and malnutrition. IAMA 2004;291:451-9.

25 Costa J, Borges M, David C, Carneiro AV. Efficacy of lipid lowering drug treatment for diabetic and non-diabetic patients: meta-analysis of randomised controlled trials. BMJ 2006;332:1115-24.

26 United States Renal Data System. Mortality and cause of death. 2007. www.usrds.org/2007/ref/H_morte_07.pdf.

27 Baigent C, Landry M. Study of heart and renal protection (SHARP). Kidney Int 2003;84:S207-10.

28 Fellstrom BC, Holdaas H, Jardine AG. Why do we need a statin trial in hemodialysis patients? Kidney Int 2003;84:S204-6.

29 Lin J, Hu FB, Rimm EB, Rifai N, Curhan GC. The association of serum lipids and inflammatory biomarkers with renal function in men with type II diabetes mellitus. Kidney Int 2006;69:336-42.

30 Wheeler DC, Bernard DB. Lipid abnormalities in the nephrotic syndrome: causes, consequences, and treatment. Am J Kidney Dis 1994;23:331-46.

31 Massy ZA, Ma JZ, Louis TA, Kasiske BL. Lipid-lowering therapy in patients with renal disease. Kidney Int 1995;48:188-98.

32 Navaneethan SD, Shrivastava R. HMG CoA reductase inhibitors (statins) for dialysis patients. Cochrane Database Syst Rev 2004;(4):CD004289

33 Stern RH, Yang BB, Horton M, Moore S, Abel RB, Olson SC. Renal dysfunction does not alter the pharmacokinetics or LDL-cholesterol reduction of atorvastatin. I Clin Pharmacol 1997;37:816-9.

34 Halstenson CE, Triscari J, DeVault A, Shapiro B, Keane W, Pan H. Single-dose pharmacokinetics of pravastatin and metabolites in patients with renal impairment. / Clin Pharmacol 1992;32:124-32.

35 Sotiriou CG, Cheng JW. Beneficial effects of statins in coronary arter disease-beyond lowering cholesterol. Ann Pharmacother 2000;34:1432-9.

36 Robinson JG, Smith B, Maheshwari N, Schrott H. Pleiotropic effects of statins: benefit beyond cholesterol reduction? A meta-regression analysis. J Am Coll Cardiol 2005;46:1855-62.

37 Kinlay S, Selwyn AP. Effects of statins on inflammation in patients with acute and chronic coronary syndromes. Am J Cardiol 2003;91:9-13B.

38 Keane WF. The role of lipids in renal disease: future challenges. Kidney Int 2000;75:S27-31

39 Campese VM, Nadim MK, Epstein M. Are 3-hydroxy-3-methylglutaryl$\mathrm{CoA}$ reductase inhibitors renoprotective? I Am Soc Nephrol 2005;16:S11-7.

40 Sica DA, Gehr TW. 3-Hydroxy-3-methylglutaryl coenzyme A reductas inhibitors and rhabdomyolysis: considerations in the renal failure patient. Curr Opin Nephrol Hypertens 2002;11:123-33.

Accepted: 11 January 2008 